\title{
Effiziente Prozessgestaltung im Erd- und Straßenbau durch den Einsatz von satellitengestützten Entscheidungsunterstützungssystemen
}

\author{
WIRTSCHAFTSINFORMATIK 50(4)2008: 305-313
}

DOI 10.1007/s11576-008-0132-z

\author{
Die Autoren \\ Prof. Dr. Peter Rausch \\ Hochschule Coburg \\ Fakultät Betriebswirtschaft - \\ Wirtschaftsinformatik \\ Friedrich-Streib-Str. 2 \\ 96450 Coburg \\ Deutschland \\ rausch@hs-coburg.de \\ Prof. Dipl.-Ing. Fritz Schreiber \\ Hochschule Coburg \\ Fakultät Design - \\ Studiengang Bauingenieurwesen \\ Friedrich-Streib-Str. 2 \\ 96450 Coburg \\ Deutschland \\ schreibe@fh-coburg.de \\ Prof. Dr. Michael Diegelmann \\ Fachhochschule Rosenheim \\ Hochschulstraße 1 \\ 83024 Rosenheim \\ Deutschland \\ Michael.Diegelmann@gmx.de \\ Die Online-Version des Originalar- \\ tikels können Sie unter http://www. \\ springerlink.com/openurl.asp?genre \\ =article\&id=doi:10.1365/s11576-008- \\ 0063-8 finden.
}

Im Beitrag „Effiziente Prozessgestaltung im Erd- und Straßenbau durch den Einsatz von satellitengestützten Entscheidungsunterstützungssystemen" von Rausch et al. (WIRTSCHAFTSINFORMATIK 50(4) 2008, S. 305-313) wurden die Bilder 2 und 5 vertauscht. Wir bitten um Entschuldigung und drucken die Bilder hier noch einmal korrekt.

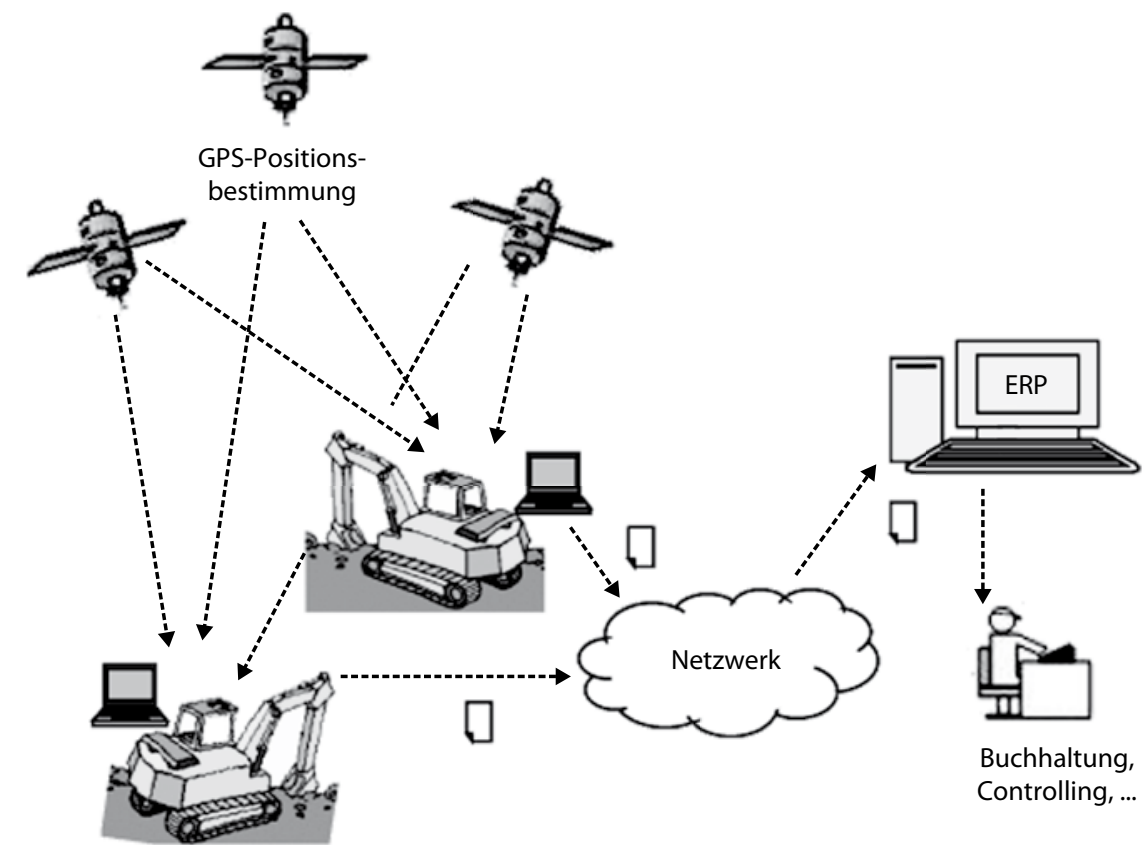

Bild 2 Erhebung und Auswertung der Daten

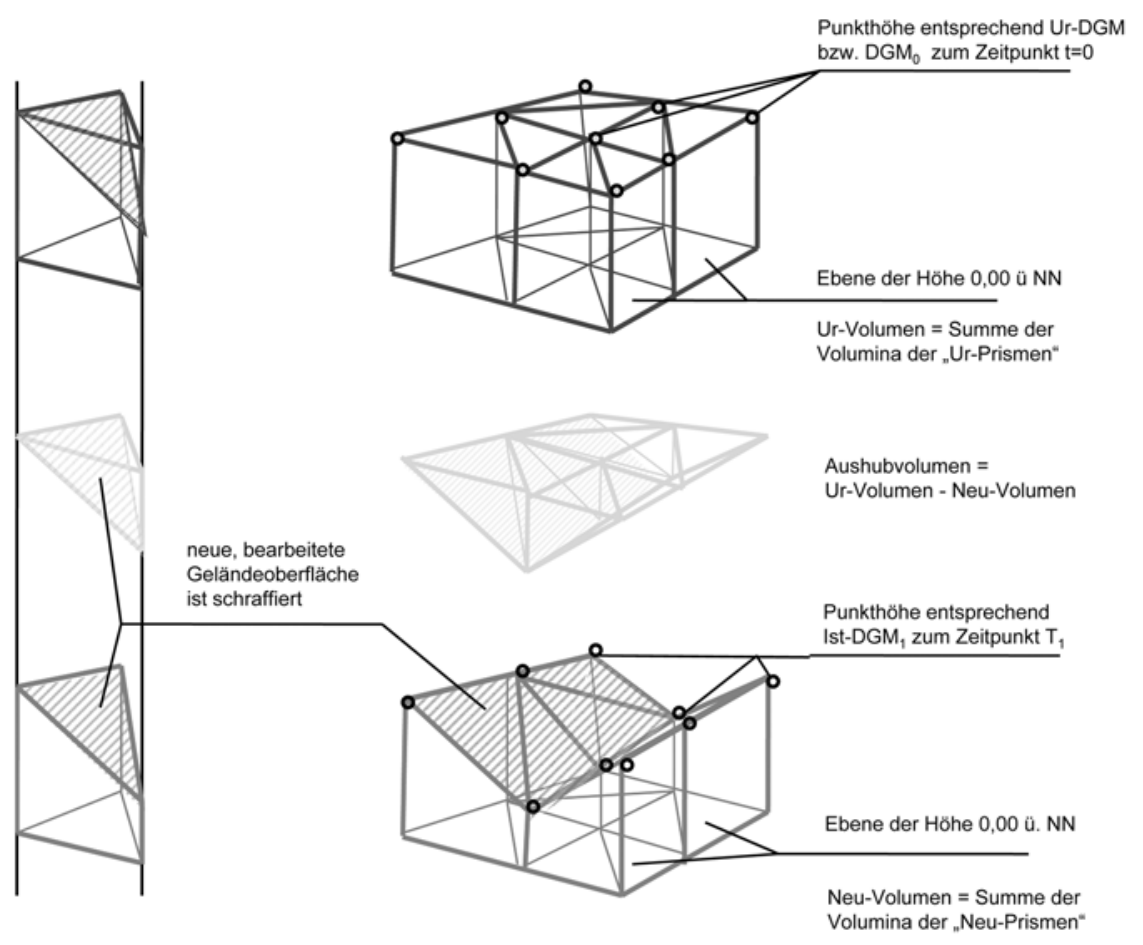

Bild 5 Prinzip der Aushub-/Leistungsermittlung durch die On-board-Software 